\title{
Efeito-fronteira em Goiás: Uma análise de seus impactos no comércio intranacional $e$ internacional
}

\author{
Andréa Freire de Lucena \\ Universidade Federal de Goiás - Goiânia - GO - Brasil \\ ORCID: http://orcid.org/0000-0003-2984-3688 \\ Frederico Teodoro da Silva \\ Universidade Federal de Goiás - Goiânia - GO - Brasil \\ ORCID: http://orcid.org/0000-0002-2570-9775 \\ Edson Roberto Vieira \\ Universidade Federal de Goiás - Goiânia - GO - Brasil \\ ORCID: http://orcid.org/0000-0002-6563-7702
}

\section{Resumo}

O objetivo deste trabalho é explicar o quanto o efeito-fronteira interferiu nas negociações comerciais goianas no ano de 2009. Esse efeito foi estimado empiricamente por meio do estimador Poisson Pseudo-Maximum-Likelihood (PPML), utilizando dados de corte seccional para os 20 principais parceiros comerciais internacionais do Estado de Goiás, mais 26 Unidades Federativas brasileiras. Mesmo que Goiás venha expandindo os produtos comercializados por meio dos incentivos de políticas públicas e por meio da capacidade empreendedora dos agentes econômicos, os resultados encontrados no estudo indicam que os produtos comercializados por Goiás são, em sua maioria, da agroindústria e que o comércio goiano com as Unidades Federativas brasileiras é significativamente maior do que o comércio com regiões internacionais, apontando assim um forte viés doméstico. Para as Unidades Federativas brasileiras que dividem fronteiras com Goiás, os resultados dão pistas de que o comércio é, em média, maior do que com as demais.

Palavras-Chave: Efeito-Fronteira. Modelo Gravitacional. Exportações. Brasil. Goiás.

\section{Border effect in Goiás: an analysis of its impacts on intranational and international trade}

\section{Abstract}

This paper seeks to explain how the border effect interfered in the Goiás trade negotiations in 2009. This effect was empirically estimated by Poisson Pseudo-Maximum-Likelihood (PPML) estimator, using sectional data for the 20 main international trading partners of the State of Goiás plus the 26 Brazilian federative units. Even though Goiás is expanding the commercialized products through public policy incentives and through the entrepreneurial capacity of economic agents, the results found in this study indicate that the products 
marketed by Goiás are mostly agroindustry and that the Goiás trade between the Brazilian federative units is many times greater than trade with international regions, thus indicating a strong home bias. For the Brazilian federative units that share borders with Goiás, the results show that the trade is, on average, greater than with the others.

Keywords: Border Effect. Gravity Model. Exports. Brazil. Goiás.

\section{Efecto frontera en Goiás: un análisis de sus impactos em el comercio intranacional y internacional}

\section{Resumen}

El objetivo de este trabajo es explicar cuánto el efecto frontera interfirió en las negociaciones comerciales en Goiás en 2009. Este efecto se estimó empíricamente utilizando la técnica Poisson Pseudo-Maximum-Likelihood (PPML) y utilizando datos de corte seccional para los 20 principales socios comerciales internacionales del Estado de Goiás, más las 26 Unidades Federativas brasileñas. A pesar de que Goiás ha estado expandiendo productos vendidos a través de incentivos de políticas públicas y a través de la capacidad empresarial de los agentes económicos, los resultados encontrados en este trabajo indican que los productos vendidos por Goiás son, en su mayor parte, del agronegocio y que el comercio de Goiás entre las Unidades Federativas brasileñas es mayor que el comercio con regiones internacionales, lo que apunta a un fuerte sesgo interno. Para las Unidades Federativas que comparten fronteras con Goiás, los resultados muestran que el comercio es, en media, mayor que con las demás.

Palabras clave: Efecto frontera. Modelo Gravitacional. Exportaciones. Brasil. Goiás.

\section{Introdução}

O comércio tem deixado de ser apenas intranacional e o mercado mundial tem se tornado uma possibilidade cada vez mais real para muitos países. A redução do custo de transporte faz com que as fronteiras físicas sejam reduzidas em termos de importância, aumentando a diversidade dos produtos disponíveis, aquecendo o comércio interno e elevando o bem-estar dos países. Porém, embora sejam menores, as barreiras ao comércio externo ainda existem, sejam elas tarifárias ou não, impondo custos a este tipo de comércio, diferentemente do que se verifica no comércio intranacional. Esses custos, por sua vez, podem levar à ocorrência do chamado efeito-fronteira, que se caracteriza quando há um viés ao comércio doméstico em relação ao comércio internacional.

Para mensurar esse viés doméstico, usualmente são utilizados modelos gravitacionais. O pioneiro em usar esse modelo para medir o efeito-fronteira foi McCallum (1995), que estimou o impacto das fronteiras no padrão de comércio entre as províncias de seu país, o Canadá, e alguns estados norte-americanos. Outros autores estimaram diferentes variações do modelo gravitacional, como Anderson e van Wincoop (2003), que incluíram na equação a distância relativa ponderada pelo Produto Interno Bruto (PIB) das economias, além de introduzir novas variáveis que poderiam captar os diferentes custos de oportunidade, a fim de encontrar resultados cada vez mais próximos dos reais custos de comércio relacionados às fronteiras.

A utilização do modelo gravitacional para medir o viés doméstico do comércio brasileiro em relação à comercialização internacional foi estudada de forma pioneira por Hidalgo e Vergolino (1998), que, ao analisar os impactos das 
fronteiras no padrão comercial da região Nordeste com o resto do país e com o exterior, concluíram que aquela região apresenta um forte viés doméstico em seu comércio. A análise do efeito-fronteira para o Brasil e suas regiões foi feita ainda por Silva et al. (2007), Daumal e Zignago (2008), Silva e Almeida (2009), Leusin Jr e Azevedo (2009), Farias e Hidaldo (2012) e Figueiredo et al. (2014).

Neste sentido, um dos diferenciais deste trabalho diz respeito à análise do efeito-fronteira com foco no estado de Goiás. Este estado teve sua política industrial nos últimos 40 anos do século XX dividida em duas fases. A primeira, que começou em 1960, teve como característica a forte intervenção desenvolvimentista do Estado, que criou políticas de incentivo ao desenvolvimento regional e perdeu forças a partir da crise fiscal-financeira. A segunda fase, conhecida como de desconcentração industrial, iniciou-se em meados da década de 1980 e foi marcada pelos incentivos gerados pelas políticas fiscais estaduais. O estado de Goiás, neste período, passou a ocupar posição de destaque na indústria de transformação de alimentos e de minerais não metálicos, que são segmentos intensivos em recursos naturais e, mais recentemente, ganhou espaço nas indústrias intensivas em escala e trabalho (ARRIEL, 2010).

O resultado das políticas de incentivo ao desenvolvimento do estado permitiu que, na década de 1980, o excedente criado pela agropecuária fosse distribuído em escala local, nacional e internacional. Os centros de distribuição estavam localizados nas áreas urbanas e as agroindústrias ocupavam a periferia desses centros. A indústria de processamento de alimentos foi o setor que mais se desenvolveu em Goiás, mas, com a diminuição dos incentivos do governo brasileiro, o estado teve que procurar novas maneiras de atrair investimentos, começando, assim, a criar políticas públicas, especialmente com o uso do Imposto sobre Circulação de Mercadorias, que era então sua principal fonte de receita tributária (ESTEVAM, 1997).

No início do século XXI, além da intensificação nas políticas de atratividade, o estado se concentrou nas políticas de incentivo às condições de permanência das empresas industriais. Em 2000, o governo de Goiás criou o Produzir, programa que visava o desenvolvimento de setores na indústria goiana com o objetivo de diversificar a economia, além de outros programas de incentivos fiscais, que permitiram a entrada de indústrias, cujo foco era o mercado exterior (PASCHOAL, 2009). Nesta linha, a agroindústria, que é composta pelo conjunto das indústrias de alimentos, bebidas e fabricação de álcool, representava em 2007 46,90\% do Valor da Transformação Industrial (VTI) da indústria goiana, que é a diferença entre o Valor Bruto da Produção Industrial (VBPI) e o Custo com as Operações Industriais (COI). Ainda que significativo, esse valor é inferior ao encontrado em 1996, quando a agroindústria representava $53,06 \%$ do $\mathrm{VTI}$, indicando que, embora a agroindústria ainda represente uma grande parcela das indústrias goianas, há diversificação da produção e, consequentemente, das exportações do estado de Goiás (ARRIEL, 2010).

Uma questão que ainda não foi respondida pela literatura que trata do efeito-fronteira no Brasil é o tamanho do viés doméstico de comércio do estado de Goiás. Por isso, uma pergunta é feita: o efeito-fronteira em Goiás influencia o comportamento do comércio goiano intranacional vis-à-vis o internacional? Com o intuito de se diferenciar dos demais trabalhos que calculam o efeito-fronteira 
utilizando apenas dados para anos até 1999, decidiu-se, então, utilizar os dados de comércio do ano de 2009, pois, ao procurar dados similares aos produzidos por Vasconcelos (2001), o ano de 2009 possuía uma proxy das informações consolidadas para o comércio interestadual no país, informações que não foram encontradas para uma data mais recente.

A metodologia utilizada nesse trabalho baseia-se na modelagem econométrica, com o cálculo do efeito-fronteira a partir de um modelo gravitacional, cujos parâmetros serão aferidos por meio do estimador Poisson Pseudo-Maximum-Likelihood (PPML). Este método também torna o artigo diferente da grande maioria dos estudos anteriores que analisou o efeito-fronteira com a perspectiva da economia brasileira, já que o método predominante utilizado em nessas estimações foi o dos Mínimos Quadrados Ordinários (MQO).

O levantamento das informações utilizadas no trabalho se iniciou com a procura de uma base de dados que contivesse, assim como feito por Vasconcelos (2001), um registro do comércio interestadual brasileiro, em específico, que mostrasse a relação de Goiás com as demais Unidades Federativas brasileiras. 0 mais próximo desses dados foi apresentado por Romanatto et al. (2011) que, para o ano de 2009, coletaram informações das exportações goianas para as demais Unidades Federativas brasileiras por meio da movimentação de mercadorias e serviços sujeitos à tributação do Imposto sobre Circulação de Mercadorias e Prestação de Serviços (ICMS).

Com uma proxy para a matriz comercial interestadual encontrada, teve início a coleta dos demais dados para o ano de 2009 utilizados no trabalho, como as exportações de Goiás para principais parceiros internacionais obtidas por meio do Comex Stat do Ministério da Economia; os Produtos Internos Brutos (PIBs) de 20 países e os PIBs estaduais das 26 Unidades Federativas brasileiras que foram retirados, respectivamente, da página eletrônica do World Bank e do portal do Instituto Brasileiro de Geografia e Estatística (IBGE); as distâncias entre Goiás e os países foram retiradas do Centre d'Etudes Prospectives et d'Informations Internationales (CEPII), e, por fim, as distâncias entre Goiás e as Unidades Federativas foram extraídas da página eletrônica do Rotas Mapas. Os dados coletados foram organizados em uma planilha para efetuar as estimações dos modelos por meio do software Stata.

\section{0 modelo gravitacional e o efeito-fronteira}

Segundo Leusin Jr. e Azevedo (2009), existem duas abordagens para se analisar o efeito-fronteira. A primeira delas é o enfoque internacional, por meio do qual se examina o impacto das fronteiras nacionais sobre o comércio internacional de um país, a fim de se mensurar o tamanho do viés de comércio intranacional vis-àvis o comércio internacional. Neste caso, a ferramenta mais usada é o modelo gravitacional, já que com ele é possível calcular o coeficiente que mede o tamanho do viés entre o comércio interno e internacional de um país. O segundo enfoque da análise do efeito-fronteira é a avaliação intranacional do efeito, mensurando o impacto nacional por meio do fluxo do comércio entre as Unidades Federativas da Nação. O pioneiro na utilização do modelo gravitacional para medir o viés do comércio intranacional e internacional foi McCallum (1995), que estimou o seguinte 
modelo para o Canadá-Estados Unidos por meio do método dos Mínimos Quadrados Ordinários (MQO):

$\operatorname{LnX} X_{i j}=\beta_{0}+\beta_{1} L n Y_{i}+\beta_{2} L n Y_{j}+\beta_{3} L n D I S T_{i j}+\beta_{4} D u m m y_{i j}+\varepsilon_{i j}$

em que $X_{i j}$ são as exportações nominais da província/estado $i$ para a província/estado $j ; Y_{i}$ e $Y_{j}$ são o PIB nominal das província/estado $i$ e $j ; D I S T_{i j}$ é a distância entre as província/estado $i$ e $j$; Dummy $y_{i j}$, que assume o valor 1 no caso de exportações intraprovinciais do Canadá e zero para exportações de províncias canadenses para estados norte-americanos e $\varepsilon_{i j}$, que é o erro.

A base de dados utilizada pelo autor foi composta por 10 províncias canadenses, 20 estados mais populosos dos Estados Unidos, mais 10 estados que fazem divisa com o Canadá, sendo utilizadas informações de 1988 relativas às exportações entre o Canadá e os Estados Unidos da América (EUA). O autor afirma que os estados norte-americanos presentes na amostra correspondiam, na época, a 90\% do comércio entre Canadá e EUA. Analisando os resultados do modelo gravitacional estimado por McCallum (1995), percebe-se um forte viés doméstico dos fluxos de comércio. Segundo o modelo gravitacional, o comércio entre duas províncias canadenses era até 22 vezes maior que o comércio entre as províncias e os EUA. Esses resultados sugerem que, apesar dos acordos comerciais da época, ainda existia uma forte fronteira em relação ao comércio internacional.

Utilizando a mesma equação, Helliwell (1998) mediu o viés comercial da província de Quebec para as demais províncias canadenses e o comparou ao comércio de estados norte-americanos de semelhantes tamanhos e distâncias no período 1988 a 1990. Os resultados parecem confirmar as conclusões de McCallum (1995), encontrando um valor ainda maior, qual seja, de 26 vezes. Anderson e van Wincoop (2003) trabalharam com o modelo desenvolvido por McCallun (1995) e incluíram nele alguns termos visando corrigir o viés causado pela possível omissão de variáveis. Esses termos caracterizam a resistência multilateral, denominação que os autores deram a todas as variáveis que criam barreiras comerciais multilaterais como os custos de troca, a presença de barreiras comerciais e as distâncias entre os países.

Com esses novos termos, Anderson e van Wincoop (2003) chegaram a um viés menor que o encontrado por McCallun (1995): um coeficiente de 16,4. Mesmo assim, tal coeficiente é superior ao encontrado pelos autores no modelo para os estados dos EUA, que foi de 1,4. Esse resultado sugere que os estados americanos negociavam 1,4 vezes mais com os estados dentro do país do que com as províncias canadenses de tamanho e distância similares. Segundo os autores, essa discrepância nos coeficientes pode ser explicada pelo fato de a economia dos EUA ser maior e possuir uma grande diversidade de produtos, sendo os estados norteamericanos mais propícios a exportar para as províncias canadenses do que o contrário.

Nitsch (2000) aplicou o modelo gravitacional visando analisar o efeitofronteira na União Europeia (UE). Por se tratar de uma união econômica, esperavase que os resultados mostrassem um baixo viés doméstico, mas o autor encontrou um coeficiente igual a 10, o que significa que os países pertencentes à UE são 
propícios a negociar 10 vezes mais internamente do que com outros países de distância e tamanho parecidos.

A fim de fazer uma análise mais intranacional dos Estados Unidos, com dados de comércio interno, tanto dentro dos estados como entre eles, além da comercialização desses estados com países da Organização para a Cooperação e Desenvolvimento Econômico (OCDE), Wolf (2000) aplicou a equação utilizada por McCallun (1995) com acréscimo de variáveis de distância absoluta e relativa, adicionando ainda uma variável dummy com valor 1 para comércio intraestadual e 0 (zero) para interestadual e outra, com valor 1 se os estados são adjacentes e valor 0 (zero) se não são, captando, assim, a intensidade do comércio entre estados que dividem fronteiras. Os resultados obtidos por Wolf (2000) indicaram que os estados norte-americanos têm um comércio intraestadual 3,28 vezes maior que 0 interestadual e que estados que compartilham fronteiras comercializam 2,6 vezes mais que os que não são adjacentes. Ao retirar a variável que capta se os estados são adjacentes, houve um aumento de $20 \%$ no efeito-fronteira, dando indícios de que essa proporção do efeito-fronteira deve ser atribuída ao fato de os estados compartilharem fronteiras.

No caso do Brasil, como já mencionado, os pioneiros nos estudos relacionados ao efeito-fronteira foram Hidalgo e Vergolino (1998), que analisaram os impactos das fronteiras no padrão comercial do Nordeste com o restante do país e com o exterior. Utilizando dados de 1991 e o método dos Mínimos Quadrados Ordinários (MQO), os autores concluíram que haveria um viés comercial intranacional e que as fronteiras internacionais ainda são um grande entrave para a comercialização internacional do Nordeste.

Silva et al. (2007), com dados de corte seccional contendo todos os estados brasileiros mais o Distrito Federal e ainda 40 países, aplicaram um modelo gravitacional para o ano de 1999, com as estimativas realizadas pelo método dos Mínimos Quadrados Ordinários (MQO). Os autores encontraram um forte viés doméstico para a comercialização dos estados brasileiros e seus resultados apontaram que os estados comercializam, em média, 37,7 vezes mais entre eles do que internacionalmente. Para os autores, um dos motivos para esse viés seria o baixo grau de substituição entre os produtos domésticos e estrangeiros.

Seguindo o enfoque da análise intranacional, Daumal e Zignago (2008) apresentaram resultados do efeito-fronteira intranacional e internacional, utilizando o método de dados em painel com efeitos fixos, bem como dados de 1991 a 1999 para 25 estados brasileiros mais o Distrito Federal (o estado de Tocantins não foi considerado), além de 164 países. Duas variáveis dummy foram adicionadas à equação utilizada por Wolf (2000), uma que capta a preferência pelo comércio intraestadual, chamada "home", e outra, "Brasil", que mede o viés comercial internacional, ou seja, a importância das fronteiras nas comercializações internacionais. Os resultados obtidos pelos autores indicaram que houve uma redução do efeito-fronteira intranacional, sendo que em 1991 o coeficiente era de 19 e, em 1999, igual a 11. Isso indica que os estados, em média, negociavam 19 vezes mais internamente, entre os municípios, do que com outros estados. Esse número caiu para 11 vezes, valor menor, porém ainda grande se comparado ao valor encontrado em outros países, como EUA e Canadá. As razões para essas disparidades englobam as diferentes alíquotas de ICMS e divergências culturais e 
econômicas. Em relação ao efeito-fronteira internacional, o resultado mostrou que, em 1991, o viés era de 17 vezes, ou seja, os estados brasileiros negociavam 17 vezes mais entre eles do que internacionalmente. Em 1999, o valor subiu para 33 vezes, mostrando, assim, que as barreiras comerciais aumentaram de 1991 para 1999 (DAUMAL; ZIGNAGO, 2008).

Com a abertura comercial brasileira nos anos 1990 e ainda a criação do Mercosul, em 1991, o que se esperava seria cada vez mais uma diminuição nas barreiras para exportações e menor viés doméstico do efeito-fronteira. Segundo os resultados obtidos por Daumal e Zignago (2008), porém, houve um período em que o comércio internacional era bem interessante para os estados brasileiros, mas, com o passar do tempo, o comércio intranacional ganhou força. Embora a média do viés internacional seja grande, esses números são muito diferentes quando se olha por regiões. Os resultados obtidos por Daumal e Zignago (2008) indicam que, enquanto o coeficiente dos estados da região Norte varia entre 6,2 a 10,3, os estados das regiões Sudeste e Sul têm um coeficiente entre 1,3 e 4. Ou seja, as Regiões Sul e Sudeste, em média, negociam mais internacionalmente do que as outras regiões. Os resultados para as negociações intranacionais vão nesta mesma direção, já que os estados que negociam mais com outros estados também negociam mais internacionalmente.

Leusin Jr. e Azevedo (2009) utilizaram o método dos Mínimos Quadrados Ordinários (MQO) para mensurar o impacto das fronteiras para o Brasil e regiões, utilizando dados de 1999 para os 26 estados brasileiros mais o Distrito Federal, além de 40 países, que representavam 91\% das exportações totais do Brasil. Os autores encontraram um viés doméstico de 33, ou seja, os estados negociam 33 vezes mais entre eles do que internacionalmente, resultado semelhante aos de outros estudos feitos anteriormente. $\mathrm{Na}$ análise intranacional, a discrepância entre os coeficientes das regiões é evidente, sendo que os estados da região Nordeste negociavam 82,9 vezes mais com os estados de outras regiões do que internacionalmente, seguindo os valores de 66,5 vezes para a região Norte, 19,2 para o Centro-Oeste, 13,7 para o Sudeste, e 4,9 para o Sul. Portanto, as regiões Sul e Sudeste são as mais integradas internacionalmente.

Silva e Almeida (2009) tiveram como objetivo analisar os efeitos das barreiras tarifárias e não tarifárias sobre as exportações brasileiras e suas contribuições para o efeito-fronteira, com dados de 1999 das 27 Unidades Federativas brasileiras e as exportações destes para 76 diferentes países. Os autores estimaram equações gravitacionais por meio do método dos Mínimos Quadrados Ordinários (MQO) e ratificaram o viés doméstico que haveria para as exportações brasileiras, dando ênfase ao papel das barreiras tarifárias, que seria reforçado ainda mais pelas barreiras não tarifárias.

Farias e Hidalgo (2012) examinaram o efeito-fronteira para as regiões brasileiras no período pós-abertura comercial. Os autores chamaram a atenção para a importância do Mercado Comum do Sul (Mercosul) para aumentar o comércio da região, sublinhando que o efeito-fronteira é ainda muito importante para o comércio das regiões brasileiras, persistindo mesmo após a abertura comercial e sendo bem mais elevado do que os encontrados em trabalhos anteriores. As estimações também foram realizadas pelo mesmo método MQO. 
Mais recentemente, Figueiredo et al. (2014) utilizaram um modelo gravitacional, seguindo a estrutura da equação e as orientações de Anderson e van Wincoop (2003), e o estimaram utilizando o método dos modelos quantílicos censurados. Os autores encontraram para o efeito-fronteira resultados de menor magnitude do que os de outros trabalhos, fato que, de acordo com sua avaliação, seria decorrente de problemas de especificação e de métodos inadequados para estimar os modelos estudados anteriormente, especialmente por não tratarem do problema da heterocedasticidade de forma eficiente.

\section{Metodologia}

Os primeiros estudos empíricos, em geral, basearam-se em dados transversais para estimar modelos de gravidade, utilizando fundamentalmente 0 método dos Mínimos Quadrados Ordinários (MQO). No caso do Brasil, a grande maioria dos trabalhos que buscaram aferir o efeito-fronteira também utilizou esse método para realizar as estimações dos modelos gravitacionais. Vale destacar, contudo, que, tal qual colocam Santos Silva e Tenreyro (2006), devido à transformação logarítmica comumente realizada nas equações utilizadas para estimar modelos de comércio externo, os estimadores lineares podem ser inconsistentes na presença de heterocedasticidade, a qual, para os autores, faz parte da natureza desse tipo de dados relativos ao comércio externo. Deste modo, - MQO pode não controlar a heterogeneidade entre os países, o que tem o potencial de resultar em viés de estimativa, pois os parâmetros estimados podem variar de acordo com os países considerados.

Em suas recomendações acerca das melhores práticas em termos do uso de modelos gravitacionais, Yotov et al. (2016) sugerem que as estimações desses modelos sejam realizadas por meio do estimador Poisson Pseudo-MaximumLikelihood (PPML), desenvolvido por Santos Silva e Tenreyro (2006). Esses autores defendem que o estimador PPML, aplicado ao modelo gravitacional expresso de forma multiplicativa, considera a heterocedasticidade, que, muitas vezes, prejudica os dados comerciais. Além disso, o estimador é capaz de tirar proveito das informações contidas nos fluxos de comércio zero e sua propriedade aditiva garante que os efeitos fixos da gravidade sejam idênticos aos seus termos estruturais correspondentes (SANTOS SILVA; TENREYRO, 2006).

Cumpre ressaltar que as simulações de Monte-Carlo realizadas por Santos Silva e Tenreyro (2006), visando verificar se o estimador PPML é consistente para estimar modelos gravitacionais, deram origem a resultados empíricos robustos, levando-se em conta não apenas modelos gravitacionais mais básicos, mas também aqueles que contam com uma proxy da resistência multilateral na equação de gravidade, replicando a ideia que foi desenvolvida por Anderson e van Wincoop (2003). Não por acaso, o estimador PPML tem sido utilizado em vários trabalhos empíricos que estimaram modelos gravitacionais para analisar os determinantes do comércio externo, como é o caso de Guan et al. (2020); Gupta et al. (2019); Hoang et al. (2020); Kea et al. (2019); Lohani (2020); Osabuohien et al. (2019); Shahriar et al. (2019); Timsina et al. (2020); Vieira e Reis (2019); Wiranthi et al. (2019); e Yao et al. (2019).

Nesta perspectiva, as estimações dos modelos utilizados neste trabalho foram realizadas por meio do estimador Poisson Pseudo-Maximum-Likelihood 
(PPML), sendo utilizadas equações gravitacionais baseadas no modelo desenvolvido por Anderson e van Wincoop (2003), que surgiu da tentativa de se resolver o dilema da fronteira proposto por McCallum (1995). Assim, na equação 2, Valor_exp $p_{i j}$ é o valor exportado por Goiás (FOB), ( $i$ ), para um estado ou país, $(j) ; \beta_{0}$ é uma constante; $P I B_{j}$ é o PIB do estado ou país $j$; Dist ${ }_{i j}$ capta a distância entre a capital goiana (i) e a capital do estado ou país importador (j); $R E M^{1}$ é o termo que busca captar a resistência multilateral, sendo dado pelo inverso da distância entre a capital do estado de Goiás e a capital do estado ou país importador, ponderado pela participação do PIB deste último país no PIB mundial (quando a exportação é para outro país) ou pela participação do PIB do estado no PIB brasileiro (quando a exportação é para outro estado) no período $t$; $D_{-}$Interno $_{i j}$ é uma variável dummy que assume o valor 1 caso as exportações sejam para estados brasileiros ou o Distrito Federal e o valor o (zero) quando as exportações têm como destino outros países; e $\varepsilon_{i j}$ é o erro da equação, ou seja, todas as variáveis não apresentadas nessa equação estão contidas no erro.

$$
\text { Valor_exp }_{i j}=\beta_{0}+\beta_{1} L n P I B_{j}+\beta_{2} \text { LnDist }_{i j}+\beta_{3} R E M+\beta_{4} D_{-} \text {Interno }_{i j}+\varepsilon_{i j}
$$

Além do modelo gravitacional supracitado, outro modelo será estimado, com o intuito de calcular o quanto as exportações interestaduais são influenciadas pelo compartilhamento de fronteiras entre as regiões. Para isso, outra variável dummy ( $D$ _Fronteira) foi adicionada, assumindo o valor 1 para estados que dividem a fronteira com Goiás e o (zero) para as demais regiões, tal qual se pode ver pela equação 3:

Valor_exp $_{i j}=\beta_{0}+\beta_{1}$ LnPIB $_{j}+\beta_{2}$ LnDist $_{i j}+\beta_{3} R E M+\beta_{4} D_{-}$Interno $_{i j}+$ $\beta_{5} D_{-}$Fronteira $_{i j}+\varepsilon_{i j}$

Conforme Wooldridge (2010), a partir dos resultados das estimações das equações 2 e 3, o efeito-fronteira pode ser calculado pela equação 4, a seguir:

$$
\frac{e^{\beta_{0}+\beta_{4}}+e^{\beta_{0}}}{e^{\beta_{0}}}
$$

em que, $\beta_{0}$ é o intercepto e $\beta_{4}$ é o coeficiente da variável dummy $D_{-}$Interno $_{i j}$. Para o cálculo desse efeito buscando avaliar a relevância (ou não) das fronteiras entre Goiás e as demais Unidades da Federação para o comércio goiano, também se utiliza a equação 4 , havendo apenas a substituição de $\beta_{4}$ por $\beta_{5}$, que é o coeficiente da variável dummy, $D_{-}$Fronteir $a_{i j}$, apresentada na equação 3 .

No que tange aos dados, foram usadas na construção da variável dependente as exportações goianas para os 20 principais parceiros internacionais

\footnotetext{
${ }^{1}$ O termo utilizado aqui como proxy da resistência multilateral foi sugerido por Head e Mayer (2014), cujo cálculo é dado por: $\sum_{\mathrm{j} \neq i} 1 /\left(\right.$ Dist $\left._{i j} / \frac{P I B_{j}}{P I B w}\right)$. Feenstra (2016 apud YOTOV, 2016) sugere a inclusão dos termos exportações-ano e/ou importações-ano, o que não é recomendado no caso desse trabalho pelo fato de os dados referirem-se apenas ao ano de 2009.
} 
de Goiás ${ }^{2}$, que são oriundas a base de dados do Comex Stat do Ministério da Economia e representavam aproximadamente $85 \%$ do total das exportações goianas em 2009 (QUADRO 1). Também compõem a variável dependente as exportações goianas para outros estados do Brasil no ano de $2009^{3}$, obtidas por Romanatto et al. (2011) por meio do Sistema Integrado de Informações sobre Operações Interestaduais com Mercadorias e Serviços (Sintegra), que é um conjunto de procedimentos administrativos e de sistemas computacionais de apoio, adotado simultaneamente pelas administrações tributárias de todas as Unidades Federativas.

Cabe destacar que os dados sobre o comércio entre Goiás e as outras Unidades Federativas brasileiras utilizados nos modelos estimados podem não ser ideais. A matriz de comércio interestadual produzida por Vasconcelos (2001), por exemplo, pode ser capaz de extrair dados mais aprofundados. Nela, o autor, em posse das matrizes de comércio interestadual brasileiro que foram obtidas a partir das Secretarias da Fazenda dos estados, confronta os dados informados na entrada e na saída e, a partir deste confronto, considera o maior valor absoluto informado, diminuindo, assim, os riscos de subestimação da matriz de comércio interestadual. Todavia, tais informações não estão disponíveis para uma data diferente de 1999, sendo necessária a utilização de uma proxy para o comércio interestadual, motivo pelo qual se decidiu seguir a metodologia de Romanatto et al. (2011).

Isso é relevante para que se compreenda o porquê da utilização dos modelos unidirecionais estimados neste trabalho, haja vista que a escolha do tipo de variável dependente utilizada nos modelos gravitacionais (exportações, importações ou fluxos comerciais bilaterais), por vezes, está ligada à disponibilidade de dados ou às diferenças na confiabilidade dos dados. Ademais, Cheng e Wall (2005) defendem que a estimação de modelos unidirecionais proporciona resultados tão satisfatórios quanto os dos modelos bidirecionais, ainda que estes últimos sejam mais utilizados que os primeiros.

\footnotetext{
${ }^{2}$ Os países, em ordem decrescente de participação nas exportações goianas, são: China, Países Baixo (Holanda), Espanha, Rússia, Índia, Irã, Reino Unido, Hong Kong, Alemanha, França, Japão, Coréia do Sul, Arábia Saudita, Suíça, Tailândia, Emirados Árabes Unidos, Egito, Angola, Argélia e Indonésia.

3 Já as Unidades Federativas, também em ordem decrescente de participação no valor comprado de Goiás, são: São Paulo, Minas Gerais, Distrito Federal, Rio de Janeiro, Mato Grosso, Bahia, Tocantins, Paraná, Pará, Santa Catarina, Rio Grande do Sul, Maranhão, Pernambuco, Ceará, Mato Grosso do Sul, Espírito Santo, Amazonas, Rondônia, Piauí, Rio Grande do Norte, Paraíba, Alagoas, Sergipe, Amapá, Acre e Roraima.
} 
Quadro 1 - Vinte Principais Destinos das Exportações de Goiás em 2009 (em\%)

\begin{tabular}{cc|cc}
\hline País & Exportações (\%) & País & Exportações (\%) \\
\hline China & 20,7 & Japão & 2,3 \\
Países Baixos (Holanda) & 12,3 & Coreia do Sul & 2,2 \\
Espanha & 7,0 & Arábia Saudita & 2,2 \\
Rússia & 5,5 & Suíça & 2,0 \\
Índia & 5,3 & Tailândia & 1,9 \\
Irã & 3,8 & Emirados Árabes Unidos & 1,5 \\
Reino Unido & 3,7 & Egito & 1,4 \\
Hong Kong & 3,6 & Angola & 1,3 \\
Alemanha & 3,1 & Argélia & 1,1 \\
França & 2,6 & Indonésia & 1,1 \\
\hline Total & & $\mathbf{8 4 , 6}$ &
\end{tabular}

Fonte: Ministério da Economia, 2020. (Dados organizados pelos autores).

No que se refere às informações do Produto Interno Bruto (PIB), enquanto na equação original usada por Anderson e van Wincoop (2003) foram utilizadas duas variáveis (uma para a região de origem e outra para a região de destino), este trabalho, por estar calculando o viés doméstico de apenas um estado, utilizou apenas a variável que capta o PIB do estado ou país para o qual Goiás exporta. Os PIBs dos países selecionados foram obtidos no endereço eletrônico do World Bank a preços correntes de 2009 e os das Unidades da Federação do Brasil no portal do Instituto Brasileiro de Geografia e Estatística (IBGE). A variável que capta a distância da capital goiana com os demais parceiros comerciais foi calculada por meio da distância entre a capital de Goiás e as outras capitais brasileiras, com dados obtidos do Rota Mapas. Para os países, a distância foi obtida no Centre d'Etudes Prospectives et d'Informations Internationales (CEPII).

Outras variáveis que fazem parte dos modelos são dummies que buscam explicar a magnitude do viés doméstico das exportações goianas e, ainda, se o comércio é maior com as Unidades Federativas que fazem divisa com Goiás. Os dados denominados em valores monetários estão em dólares dos EUA. Como os dados do PIB dos estados foram obtidos originalmente em reais, esses valores foram convertidos em dólares utilizando-se uma taxa média de câmbio de 2009 (1,9927), retirada do site do Banco Central do Brasil. As distâncias estão em quilômetros, todos os dados são diferentes de zero e os painéis fortemente balanceados.

\section{Resultados e discussões}

As estimativas obtidas para os modelos de comércio entre Goiás e os outros estados brasileiros mais o Distrito Federal, bem como os 20 principais parceiros comerciais internacionais, estão apresentadas nos Quadros 2 e 3. Tendo em vista que habitualmente equações gravitacionais apresentam problemas de heterocedasticidade, os modelos foram estimados com a aplicação do estimador Poisson Pseudo-Maximum-Likelihood (PPML), visando-se obter resultados mais robustos. 
Os resultados do teste Ramsey RESET indicam que os modelos estimados não possuem omissão de variáveis, hipótese nula do teste, que não é rejeitada ao nível de $5 \%$ de significância para ambos os modelos, tais quais mostram os Quadros 2 e 3. Para as variáveis presentes nos modelos estimados, é esperado um sinal negativo apenas de $\beta_{2}$, pois com o aumento da distância é esperada uma redução nas exportações goianas. Praticamente todos os coeficientes apresentaram o sinal esperado e significância estatística aos níveis de $1 \%$ e $5 \%$, excetuando-se $\beta_{0}$ e $\beta_{2}$ referentes ao modelo 2 . No caso de $\beta_{2}$, o resultado pode decorrer do fato de os maiores importadores dos produtos goianos serem China, no âmbito internacional, e São Paulo, na dimensão intranacional. Esses importadores possuem PIBs e populações bem superiores aos dos demais parceiros comerciais nacionais e estrangeiros de Goiás.

Quadro 2 - Modelo 1 - Estimação do Efeito-Fronteira pelo Estimador PPML Variável dependente: Valor exp

\begin{tabular}{|c|c|c|}
\hline Variáveis & Coeficiente & p-valor \\
\hline Const & $\begin{array}{l}6,8995^{*} \\
(3,5725)\end{array}$ & 0,053 \\
\hline I_PIB & $\begin{array}{c}0,5399 * * * \\
(0,1195)\end{array}$ & 0,000 \\
\hline I_Dist & $\begin{array}{c}-0,3220^{* *} \\
(0,1418)\end{array}$ & 0,023 \\
\hline REM & $\begin{array}{c}4476,68 * * * \\
(1709,827)\end{array}$ & 0,009 \\
\hline D_Interno & $\begin{array}{c}3,5222 * * * \\
(0,6344)\end{array}$ & 0,000 \\
\hline \multicolumn{3}{|c|}{$\begin{array}{l}\text { N. de Observações: } 46 \\
R^{2}=0,9405 \\
\text { Teste Ramsey RESET }(\text { Prob }>F)=0,3277\end{array}$} \\
\hline
\end{tabular}

Nota: * Significante ao nível de 10\%; ** Significante ao nível de 5\%; *** Significante ao nível de $1 \%$. Erros-padrão entre parênteses.

Pelos dados do Quadro 2, pode-se ver que a influência da variação do PIB da região à qual se destina as exportações goianas (estado ou país), ou seja, que avalia o impacto que um crescimento na renda daquela localidade causa nas exportações de Goiás, é significativa ao nível de $1 \%$ de significância e tem um impacto positivo nas exportações, sugerindo que um incremento no PIB do país ou estado destinatário causa um aumento nas exportações goianas. Como os PIBs dos países destinos das exportações goianas estão representados em logaritmo, a elasticidade "PIB-valor exportado" é obtida por meio de seu coeficiente, com valor entre 0,50 (modelo 2) e 0,54 (modelo 1). Com isso, tem-se que a relação "valor exportado-PIB" é inelástica, ou seja, que o aumento de $1 \%$ no PIB do país ou estado importador provoca um incremento de aproximadamente $0,5 \%$ nas exportações de Goiás. Esse comportamento inelástico está de acordo com a literatura relativa ao efeitofronteira, que assevera que a elasticidade das exportações em relação ao PIB do estado ou país exportador é superior à elasticidade dessas exportações obtida em relação ao PIB do estado ou país importador ${ }^{4}$. Assim, tradicionalmente, a renda do

\footnotetext{
${ }^{4}$ Ver especialmente Leusin Jr. e Azevedo (2009); Silva e Almeida (2009); Farias e Hidalgo (2012); e Figueiredo et al. (2014).
} 
estado ou país exportador explica em maior grau o volume exportado entre dois parceiros do que a renda do importador.

A variável dummy $D \_I n t e r n o$, que capta o efeito-fronteira de Goiás, é significativa e positiva, sugerindo que há um viés doméstico nas exportações goianas, com um coeficiente de 3,52. Pela equação (4), que calcula o efeitofronteira, tem-se que, ceteris paribus, o comércio entre Goiás e os outros estados brasileiros é aproximadamente 34,85 vezes maior do que com o exterior. Ainda que tenha sido calculado para um estado específico e em períodos diferentes, vale ressaltar que o efeito-fronteira para Goiás é próximo aos valores encontrados em trabalhos que medem o efeito-fronteira brasileiro. Em Silva et al. (2007), o efeitofronteira do Brasil encontrado para o ano de 1999 foi de 37,7 vezes e, em Daumal e Zignago (2008), este efeito, também para o ano de 1999, foi de 32,5 vezes.

Quadro 3. Modelo 2 - Estimação do Efeito Adjacente pelo Estimador PPML Variável dependente: Valor exp

\begin{tabular}{|c|c|c|}
\hline Variáveis & Coeficiente & p-valor \\
\hline Const & $\begin{array}{c}3,2952 \\
(2,6183)\end{array}$ & 0,208 \\
\hline I_PIB & $\begin{array}{c}0,5045^{* * *} \\
(0,0963)\end{array}$ & 0,000 \\
\hline I_Dist & $\begin{array}{c}0,1668 \\
(0,1535)\end{array}$ & 0,277 \\
\hline REM & $\begin{array}{c}7449,52^{* * *} \\
(1709,827)\end{array}$ & 0,000 \\
\hline D_Interno & $\begin{array}{c}4,1870 * * * \\
(0,4806)\end{array}$ & 0,000 \\
\hline D_Fronteira & $\begin{array}{c}0,7884 * * * \\
(0,2165)\end{array}$ & 0,000 \\
\hline $\begin{array}{l}\text { N. de Observ } \\
\text { Prob. }>X^{2}=0 \\
\text { Teste Ramse }\end{array}$ & & \\
\hline
\end{tabular}

Nota: * Significante ao nível de 10\%; ** Significante ao nível de 5\%; *** Significante ao nível de $1 \%$. Erros-padrão entre parênteses.

O modelo 2, acima, foi estimado com a adição da variável dummy D_Fronteira, que tem valor 1 para os estados que fazem fronteira com Goiás e o para os demais, a fim de calcular o impacto do compartilhamento de fronteiras para as exportações. Tal variável mostrou-se estatisticamente significante a um nível de $1 \%$, mas a variável constante (Const), também necessária para se calcular o efeitofronteira, não apresentou significância aos níveis aceitáveis. A despeito disso, optou-se por realizar os cálculos dos efeitos no sentido de se apresentar pistas acerca de seus resultados para o estado de Goiás.

Assim, pode-se perceber pelo Quadro 3 que o valor do coeficiente da variável D_Interno, que capta o efeito-fronteira de Goiás, aumentou, sendo agora igual a 4,18 , levando o viés doméstico para 66,36 vezes. Por sua vez, a variável adicionada (D_Fronteira) teve impacto positivo e coeficiente de aproximadamente 0,79 , resultado que sugere que Goiás exporta 3,2 vezes mais para estados com os quais divide fronteira do que com os demais. Esse resultado acaba não se mostrando muito significativo quando comparado aos primeiros que indicam haver viés doméstico nas exportações $(34,85$ e 66,36$)$. Uma possível explicação para tanto 
pode decorrer das exportações realizadas por Goiás para o estado de São Paulo. Este estado era responsável por cerca de 30\% do total das exportações de Goiás para as outras Unidades da Federação em 2009, sendo que, como se sabe, não faz fronteira com Goiás.

\section{Considerações finais}

O presente trabalho foi elaborado a fim de compreender e mensurar o viés doméstico das exportações goianas em 2009. Para isso, foi analisado o efeito fronteira, que consiste em medir qual é o tamanho do comércio intranacional em contraposição ao comércio internacional. Com o intuito de entender melhor o efeito-fronteira, foi feita uma análise da literatura econômica que apresenta uma revisão histórica desde o início da construção do modelo, bem como alterações demandadas para melhor mensurar o efeito-fronteira.

A forma comum de se obter o efeito-fronteira é a partir do modelo gravitacional que, além das variáveis convencionais, como PIB e distância absoluta, inclui uma variável dummy associada ao comércio interestadual e/ou internacional. Essa dummy indica se o fato de o fluxo de comércio necessitar cruzar fronteiras regionais ou nacionais tem alguma influência sobre o padrão de comércio de um estado e/ou país. Os dados das exportações utilizadas nos dois modelos estimados nesse trabalho referem-se àquelas que têm origem em Goiás e como destino as outras 26 Unidades Federativas brasileiras, somadas com as 20 maiores exportações para as regiões internacionais em 2009, que constituíram aproximadamente $85 \%$ das exportações de Goiás daquele ano.

Os resultados encontrados indicam que as exportações goianas são inelásticas em relação à renda dos seus parceiros comerciais, sejam eles as outras Unidades Federativas do país ou outros países. O trabalho também procurou medir se o fato de uma determinada região dividir fronteira com Goiás teve influência nas comercializações feitas pelo Estado em 2009. As estimativas realizadas sugerem que a comercialização goiana com as UFs que fazem divisa com Goiás, embora seja maior do que com as outras UFs que não o fazem, acaba não sendo muito significativa. Esse resultado pode ter relação com o alto volume das exportações goianas destinadas ao estado de São Paulo, que não possui fronteira com Goiás.

Há indícios de forte viés doméstico nas exportações goianas. O efeitofronteira obtido com base na estimação dos parâmetros dos modelos mostra que, em 2009, Goiás comercializava aproximadamente 35 vezes mais com as Unidades Federativas brasileiras do que internacionalmente, indicando, assim, que as fronteiras, sejam elas físicas e/ou fiscais, representam um significativo entrave ao comércio para o estado de Goiás. Os resultados encontrados aqui estão entre os de Daumal e Zignago (2008) e de Silva et al. (2007), que também estudaram o efeitofronteira, mas com o foco no Brasil e não em um estado específico.

O forte viés doméstico dos fluxos do comércio goiano no ano de 2009 indica que grande parte da produção goiana é negociada com as demais Unidades Federativas brasileiras. As razões para esse significativo efeito-fronteira não puderam ser obtidas a partir dos modelos estimados, fundamentalmente por conta da inexistência de dados suficientes no momento da realização do trabalho, tais 
como aqueles relativos aos incentivos governamentais. Novas investigações podem levantar essas razões e darem sequência aos resultados encontrados.

\section{REFERÊNCIAS}

ANDERSON, J. E.; van WINCOOP, E. Gravity with gravitas: a solution to the border puzzle. The American Economic Review, v. 93, p. 170-192, 2003.

ARRIEL, M. F. Perfil Produtivo e Dinâmica Espacial da Indústria Goiana - (19992007). 2010. Dissertação (Mestrado em Desenvolvimento e Planejamento Territorial) - Departamento de Ciências Econômicas, Pontifícia Universidade Católica de Goiás, Goiânia, 2010.

BANCO CENTRAL DO BRASIL. Sistema Gerenciador de séries temporais. Disponível em:

https://www3.bcb.gov.br/sgspub/localizarseries/localizarSeries.do?method=prepara rTelaLocalizarSeries. Acesso em: 15 fev. 2020.

BANCO MUNDIAL. Indicators. Disponível em: https://data.worldbank.org/indicator. Acesso em: 25 ago. 2020.

CEPII - CENTRE FOR PROSPECTIVE STUDIES AND INTERNATIONAL INFORMATION. GeoDist. Disponível

em: http://www.cepii.fr/CEPII/en/bdd_modele/presentation.asp?id=6. Acesso em: 18 nov. 2019 .

CHENG, I., WALL, H. Controlling for Heterogeneity in Gravity Models of Trade and Integration, Federal Reserve Bank of St. Louis Review, 2005, p. 49-61.

DAUMAL, M.; ZIGNAGO, S. The border effects in Brazil. Paris: Centre d'Études Prospectives et d'Informations Internationales, 2008. (Working Paper, n. 2008-11). Disponível em: http://www.cepii.fr/PDF_PUB/wp/2008/wp2008-11.pdf. Acesso em: 02 mar. 2020.

ESTEVAM, L. A. O Tempo da Transformação: Estrutura e Dinâmica na Formação Econômica de Goiás. 1997. Tese (Doutorado em Economia) - Instituto de Economia, Universidade Estadual de Campinas, Campinas, 1997.

FARIAS, J. J. de; HIDALGO, Á. B. Comércio interestadual e comércio internacional das regiões brasileiras: uma análise utilizando o modelo gravitacional. Revista Econômica do Nordeste, v.43, n.2, p.251-266, 2012.

FIGUEIREDO, E., et al. Uma análise para o efeito-fronteira no Brasil. Revista Brasileira de Economia, v.68, n.4, p.481-496, 2014. 
FEENSTRA, R. C. Advanced International Trade: Theory and Evidence. Princeton: Princeton University Press, 2016.

GUAN, Z.; SHEONG, J. K. F. Determinants of bilateral trade between China and Africa: a gravity model approach. Journal of Economic Studies, v. 47, n. 5, p. 10151038, 2020.

GUPTA, R.; GOZGOR, G.; KAYA, H.; DEMIR. E. Effects of geopolitical risks on trade flows: evidence from the gravity model. Eurasian Economic Review, v. 9, n. 4, p. 515530, 2019.

HEAD, K.; MAYER, T. Gravity equations: Workhorse, toolkit, and cookbook. In: GOPINATH, G.; HELPMAN, E.; ROGOFF, K. (Ed.). Handbook of international economics. Amsterdam: Elsevier, 2014. p. 131-195.

HELLIWELL, J. F. How much do national borders matter? Washington D. C.: Brookings Institution Press, 1998.

HIDALGO, Á. B.; VERGOLINO, J. R. O Nordeste e o comércio inter-regional e internacional: Um teste dos impactos por meio do modelo gravitacional. Economia Aplicada, v. 2, n. 4, p. 707-725, 1998.

HOANG, N. T. T.; TRUONG, H. Q.; VAN DONG, C. Determinants of Trade between Taiwan and ASEAN Countries: A PPML Estimator Approach. SAGE Open, v. 10, n. 2, p. 1-13, 2020.

INSTITUTO BRASILEIRO DE GEOGRAFIA E ESTATÍSTICA - IBGE. Sistema de Contas Regionais - SCR. Disponível em: https://www.ibge.gov.br/estatisticas/economicas/contas-nacionais/9054-contasregionais-do-brasil. Acesso em: 25 ago. 2020.

KEA, S.; SHAHRIAR, S.; ABDULLAHI, N. M.; PHOAK, S.; TOUCH, T. Factors Influencing Cambodian Rice Exports: An Application of the Dynamic Panel Gravity Model. Emerging Markets Finance and Trade, v. 55, n. 15, p. 3631-3652, 2019.

LEUSIN JR., S.; AZEVEDO, A. O efeito fronteira das regiões brasileiras: Uma aplicação do Modelo Gravitacional. Revista de Economia Contemporânea, v. 13, p. 229-258, 2009.

LOHANI, K. K. Trade Flow of India with BRICS Countries: A Gravity Model Approach. Disponível em: https://www.researchgate.net/publication/341098115_Trade_Flow_of_India_with_B RICS_countries_A_Gravity_Model_Approach. Acesso em: 29 ago. 2020.

MCCALLUM, J. National borders matter: Canada-U.S. regional trade patterns. The American Economic Review, v. 85, n. 3, p. 615-23, 1995. 
MINISTÉRIO DA ECONOMIA. Comex Stat. Disponível em: http://comexstat.mdic.gov.br/pt/home. Acesso em: 25 jan. 2020.

NITSCH, V. National borders and international trade: evidence from the European Union. Canadian Journal of Economics/Revue canadienne d'économique, v. 33, n. 4, p. 1091-1105, 2000.

OSABUOHIEN, E. S.; EFOBI, U. R.; ODEBIYI, J. T.; FAYOMI, O. O.; SALAMI, A. O. Bilateral trade performance in West Africa: A gravity model estimation. African Development Review, v. 31, n. 1, p. 1-14, 2019.

PASCHOAL, J. A. R. O Papel das Políticas Públicas de Incentivos e Benefícios Fiscais no Processo de Estruturação Industrial de Goiás 2000 - 2008. Conjuntura Econômica Goiana, v. 12, p. 41-53, 2009.

ROMANATTO, E.; OLIVEIRA, D. V.; ARRIEL, M. F.; MARQUES, D. F. Comércio Interestadual de Goiás: uma análise para 2009. Boletim Regional Urbano e Ambiental, n. 5, p. 37-49, jun. 2011.

ROTA MAPAS. Rotas, mapas e distâncias entre cidades do Brasil. Disponível em: https://www.rotamapas.com.br/. Acesso em: 10 mar. 2020.

SANTOS SILVA, J.M.C.; TENREYRO, S. The log of gravity. The Review of Economics and Statistics, v.88, p. 641-658, 2006.

SILVA, O. M.; ALMEIDA, F. M.; OLIVEIRA, B. M. Comércio internacional $x$ intranacional no Brasil: medindo o efeito-fronteira. Nova Economia, v. 17, n. 3, p. 427-439, 2007.

SILVA, O. M.; ALMEIDA, F. M. de. Uma estimativa da contribuição tarifária para o efeito-fronteira no Brasil. Economia Aplicada, v.13, n.3, p.463-474, 2009.

SHAHRIAR, S.; QIAN, L.; KEA, S. Determinants of exports in China's meat industry: A gravity model analysis. Emerging Markets Finance and Trade, v. 55, n. 11, p. 25442565, 2019.

TIMSINA, K. P.; CULAS, R. J. Do Free Trade Agreements Increase Australian Trade: An Application of Poisson Pseudo Maximum Likelihood Estimator? Journal of EastWest Business, v. 26, n. 1, p. 56-80, 2020.

VASCONCELOS, J. Matriz de fluxo do comércio interestadual no Brasil - 1999. Brasília: IPEA, 2001. (Texto para Discussão, n. 817).

VIEIRA, E. R.; REIS, D. H. A. Determinants of Brazilian exports by levels of technological intensity: a gravity model analysis using the PPML estimator. Journal of Business and Economics, v.10, n.9, p. 861-879, 2019. 
WOLF, H. C. Intranational home bias in trade. Review of economics and statistics, v. 82, n. 4, p. 555-563, 2000.

WIRANTHI, P. E.; AMINUDIN, I.; DEWI, E. R. A Gravity Model for Indonesian Canned Tuna Exports to the European Union Market: An Application of PPML Estimator. Sriwijaya International Journal of Dynamic Economics and Business, v. 3, n. 1, p. 31-52, 2019.

WOOLDRIDGE, J. M. Introdução à Econometria: uma abordagem moderna. São Paulo: Cengage, 2010.

WORLD BANK. Indicators. Disponível em: https://data.worldbank.org/indicator. Acesso em: 10 fev. 2020.

YAO, X.; YASMEEN, R.; LI, Y.; HAFEEZ, M.; PADDA, I. U. H. Free trade agreements and environment for sustainable development: a gravity model analysis. Sustainability, v. 11, n. 3, p. 1-17, 2019.

YOTOV, Y.; PIERMARTINI, R.; MONTEIRO, J. A.; LARCH, M. An Advanced Guide to Trade Policy Analysis: The Structural Gravity Model. Geneva: World Trade Organization, 2016.

Andréa Freire de Lucena. Doutora em Relações Internacionais. Professora associada do curso de Ciências Econômicas da Faculdade de Administração, Ciências Contábeis e Ciências Econômicas (FACE). E-mail: andflucena@gmail.com

Frederico Teodoro da Silva. Graduado em Ciências Econômicas (UFG). Analista de negócios no segmento de seguros. E-mail: mkfred@gmail.com

Edson Roberto Vieira. Doutor em Economia Aplicada (UFU). Professor adjunto da Universidade Federal de Goiás (UFG) e Superintendente do Instituto Brasileiro de Geografia e Estatística (IBGE) em Goiás. E-mail: er_vieira@hotmail.com

Como citar: DE LUCENA, Andréa Freire; DA SILVA, Frederico Teodoro; VIEIRA, Edson Roberto. Efeito-fronteira em Goiás: uma análise de seus impactos no comércio intranacional e internacional. Redes (St. Cruz Sul, Online), Santa Cruz do Sul, v. 25, p. 2549-2567, 2020. doi:https://doi.org/10.17058/redes.v25i0.15077. 


\section{CONTRIBUIÇÃO DE CADA AUTOR}

a. Fundamentação teórico-conceitual e problematização: Andréa Freire de Lucena e Frederico Teodoro da Silva

b. Pesquisa de dados e análise estatística: Frederico Teodoro da Silva e Edson Roberto Vieira

c. Elaboração de figuras e tabelas: Frederico Teodoro da Silva e Edson Roberto Vieira

d. Fotos: não se aplica

e. Elaboração e redação do texto: Andréa Freire de Lucena, Frederico Teodoro da Silva e Edson Roberto Vieira

f. Seleção das referências bibliográficas: Andréa Freire de Lucena, Frederico Teodoro da Silva e Edson Roberto Vieira

Fontes de financiamento: não se aplica. 